\title{
O Ser Psicanalista
}

\author{
Mário Andrade dos Santos \\ Psicólogo Clínico. Psicanalista. Psicoterapeuta - mariojasantos@sapo.pt
}

\begin{abstract}
Resumo
O autor, tendo por base a obra completa de seus analisandos. Salientando como essenSigmund Freud, pretendeu realçar a importância fundamental do funcionamento mental do psicanalista e da sua disponibilidade cial na formação psicanalítica a análise pessoal que possibilite o tender e o realizar-se naquilo que verdadeiramente se é.
\end{abstract} interna para o processo analítico com os

Palavras-chave: Psicanálise, nova relação, função psicanalítica da personalidade, verdadeiro self, expansão da mente.

\section{Being a Psychoanalyst}

\begin{abstract}
The author, based on the complete work of Sigmund Freud, sought to emphasize the fundamental importance of the psychoanaanalysands. Emphasizing as essential in the psychoanalytic formation the personal analysis that makes it possible to tend and to reallyst's mental functioning and his internal ize oneself in what it truly is.
\end{abstract} availability for the analytical process with his

Keywords: Psychoanalysis, new relationship, psychoanalytic function of personality, true self, expansion of mind.

\section{I}

À semelhança das operações matemáticas da soma, subtração, multiplicação e divisão, onde é impossível decorar todos os resultados finais resultantes de infinitas combinações dos elementos participantes nas operações, também na psicanálise é impossível conhecer antecipadamente as interpretações para as infinitas relações que se operam na vida mental de cada indivíduo. Na matemática como na psicanálise o importante é o método, o matemático e o psicanalítico. Com eles conseguimos obter 
respetivamente o resultado do produto de cada operação matemática e as interpretações correspondentes às conjugações dos elementos mentais num determinado cenário relacional, emocional e do pensar intra e interpessoal.

\section{II}

A psicanálise na vertente clínica tenta ajudar o paciente a libertar-se do seu funcionamento psíquico patológico causador de dor mental através da relação psicanalista-analisando, na qual sentindo-se amado, apreciado e entendido, permite-lhe progressiva consciência da sua essência interna e nela ir-se realizando.

O ser psicanalista é trabalhar com o paciente nesta função psicanalítica e mantê-la viva dentro de si mesmo.

\section{III}

Ao percorrer toda a obra de Sigmund Freud, para a realização deste trabalho, fui notando os pensamentos do autor que se entrelaçavam com o tema que pretendo abordar, a importância da pessoa do psicanalista para o seu modo de estar na relação analítica.

Sigmund Freud foi o criador da psicanálise, homem da ciência e da cultura, que revela ao longo da sua obra a veia de investigador e inovador, não temendo pôr em causa as suas próprias ideias sempre que acontecimentos recentes as comprometiam, substituindo-as, quando necessário, por outras mais adequadas à interpretação das novas realidades, das dinâmicas mentais, fazendo assim evoluir a psicanálise. Não só a criou como sinalizou vias que foram sendo exploradas pelos psicanalistas, essas e outras que não chegaram a ocorrer à genialidade de Freud. As nossas vidas não são eternas e o saber vai-se construindo com os contributos das sucessivas gerações humanas.

\section{IV}

Começo por realçar a ideia de Freud, 1889, que aquele que "já começa [a atividade de hipnotizar, neste caso a de exercer a psicanálise] com estado de ânimo vacilante, conseguirá pouca coisa" (Freud, 1889/1996, p. 137), pois é da adesão interna às te- 
orias psicanalíticas e da convicção do poder curativo/transformador do seu método psicoterapêutico que o psicanalista manterá firme a sua esperança de ser capaz de ajudar os seus pacientes na resolução da sua dor mental, nos momentos mais difíceis e conturbados do processo analítico. Esta é, penso, a trave mestra onde assenta a motivação de ser psicanalista.

\section{V}

O psicanalista é muito mais do que um técnico virtuoso de psicanálise, é uma pessoa que se relaciona com outra (analisando), e que pela atitude disponível e acolhedora, pela sua personalidade madura, experiência de vida e cultura geral associadas à competência profissional, vai criando condições de trabalho analítico que o ajudam a entender o seu analisando. A este pensamento conduziu-nos Freud quando nos fala da "expectativa confiante" (Freud, 1905/1996) do doente relativamente à medicina (psicanálise) e ao médico (psicanalista) como fator influente no resultado terapêutico, e quando em, 1926, diz que:

Para ele [paciente] é [...] importante que o analista deva possuir qualidades pessoais que o tornem digno de confiança, e que ele deva ter adquirido o conhecimento e a compreensão, bem como a experiência, que, somente estes, possam tornar-lhe possível cumprir sua tarefa [analítica] [...] A análise, à qual todos os candidatos [...] têm de submeter-se, é ao mesmo tempo o melhor meio de formar um[a] opinião sobre a sua aptidão pessoal para o desempenho da sua exigente profissão (Freud, 1926-1927/1996, p. 235).

E, também, quando em 1913 refere que no processo psicanalítico "A extraordinária diversidade das constelações psíquicas envolvidas, a plasticidade de todos os processos mentais e a riqueza dos fatores determinantes opõem-se a qualquer mecanização da técnica" (Freud, 1913a/1996, p. 139). Na verdade, sabemos que a dinâmica relacional entre os mundos internos do analista e do analisando é diferente de análise para análise, ao longo de cada análise e até no decorrer da mesma sessão. A confiança que o analisando deposita no analista surge, por vezes, antes do início da análise, pelas qualidades pessoais e profissionais que conhece do psicanalista, as quais vão ao encontro das suas necessidades e desejos, ou pelas que expecta ou que nele projeta, 


\section{O Ser Psicanalista}

outras vezes acontece no decorrer das sessões de análise pela relação regular e continente que o analista estabelece com o analisando. Este necessita estar confiante de que o seu analista acolherá e entenderá bem o seu mundo interno carente e fragilizado, como, por outro lado, o protegerá e não se deixará enlouquecer e destruir pela malignidade ("parte psicótica da personalidade" (Bion, 1994)) existente nesse mesmo mundo interno, revelando-lhe desse modo o seu investimento afetuoso em si.

\section{VI}

Freud, 1895, a dado passo, debruçando-se sobre a técnica do método catártico, diz:

O processo é laborioso e exige muito tempo do médico [psicoterapeuta]. Pressupõe grande interesse pelos acontecimentos psicológicos, mas também um interesse pessoal pelos pacientes. Não consigo me imaginar sondando o mecanismo psíquico de uma histeria de alguém que me causasse a impressão de ser vulgar e repelente e que, num conhecimento mais íntimo, não fosse capaz de despertar solidariedade humana, ao passo que consigo manter o tratamento de um paciente tabético ou reumático, independentemente de uma aprovação pessoal desse tipo (Freud, 1895/1996, p. 280).

Tal como no método catártico também no processo psicanalítico, o psicoterapeuta está implicado na relação com o seu paciente e esse envolvimento faz despertar nele motivações que favorecem ou condicionam o trabalho analítico. Em sentido semelhante, temos ouvido Coimbra de Matos apontar a escolha feita pelo psicanalista ou a aposta nas potencialidades do analisando, como pilar fundamental para o decurso de uma boa análise. Sendo a escolha do outro (escolher e ser escolhido) o alicerce de qualquer relação, nem sempre o analista está em condições de poder efetuar essa seleção, como por exemplo quando lhe faltam casos suficientes para trabalhar (também referido por Freud na Conferência XXVIII das Conferências Introdutórias Sobre Psicanálise (Freud, 1917b/1996). Nessas situações o psicanalista precisa estar vigilante aos seus movimentos internos adversos a essa análise, senti-los e pensá-los para que não interfiram negativamente na relação analítica, até que dessa relação emerjam fatores cativantes e estimulantes para o analista. 
O psicanalista clínico não existe sem analisando e vice-versa. A autoanálise do analista não basta para fazer e manter a mão. A atividade de psicanalisar precisa de prática, de prática sentida e pensada. O psicanalista ao acolher e pensar os mundos (interno e externo) do analisando estes vão repercutir-se nos seus, inclusive na contratransferência, criando oportunidade para analisá-los e transformá-los, principalmente aspetos de si desconhecidos ou apenas aflorados.

\section{VII}

Em nota de rodapé da Revisora Geral na primeira página do capítulo II de A Interpretação dos Sonhos (1900) lembra que este título "não expressa propriamente a ideia de uma "interpretação" (fechada, final ou única) dos sonhos, mas a de uma busca do sentido dos sonhos, evidentemente entendidos por Freud como dotados de sentido para cada sujeito ao sonhar" (Revisora Geral, Freud, 1900/1996, p. 131). E um pouco mais à frente Freud escreve "o mesmo fragmento de um conteúdo [do sonho] pode ocultar um sentido diferente quando ocorre em várias pessoas ou em vários contextos" (Freud, 1900/1996, p. 139). Realça-se aqui a importância do mundo interno de cada sujeito para a interpretação própria, diferente da de outros, dos produtos mentais que esse mesmo mundo interno gerou, salientando-se assim que cada caso é um caso. A isto podemos acrescentar a sobredeterminação do sonho, como do sintoma e outras formações do inconsciente, a qual implica que o analista não pode encerrar o sonho num único sentido (como verdade única) mas sim deixá-lo em aberto para o surgimento de novas significações.

\section{VIII}

No ano de 1904 Freud relatou que pedia aos seus pacientes que lhe comunicassem "tudo o que lhes passar pela cabeça, mesmo o que julgarem sem importância, ou irrelevante, ou disparatado [...] que não excluam de suas comunicações nenhum pensamento ou idéia pelo fato de serem embaraçosos ou penosos" (Freud, 1904/1996, p. 237). Esta regra irá surgir várias vezes em outros trabalhos posteriores nomeadamente no de 1932 e 1940. O psicanalista ao pronunciar esta regra (de associação livre, regra fundamental) do processo psicanalítico ao paciente é essencial que ele 


\section{O Ser Psicanalista}

próprio, por sua vez, não se retire da comunicação (verbal e não verbal) do analisando, nem se impeça de pensar todas as emoções e pensamentos que lhe ocorram, mas pelo contrário esteja mentalmente disponível para acolher as associações do paciente quaisquer que sejam, permitindo que sua atividade inconsciente funcione o mais livremente possível (a atenção flutuante do analista é o correspondente da associação livre do analisando). Como diz Freud:

a atitude que o médico analítico podia mais vantajosamente adotar [face às associações livres do seu paciente], era entregar-se á sua própria atividade mental inconsciente, num estado de atenção imparcialmente suspensa, a fim de evitar, tanto quando possível, a reflexão e a construção de expectativas conscientes, não tentar fixar particularmente coisa alguma que ouvisse na memória e, por esses meios, apreender o curso do inconsciente do paciente com o seu próprio inconsciente (Freud, 1923/1996, p. 256).

Contudo, nem sempre isso acontece, diversos motivos podem afastá-lo dessa comunicação (do analisando e do analista de si para si mesmo): quer como Matos (2002) referiu que aspetos internos do analista não resolvidos ao se conectarem com os que lhe transmite o paciente, causando-lhe dor mental, levam-no a evitá-los; quer por demasiado cansaço físico ou mental poder sentir a sessão como penosa, desejando o seu término; quer por intensas ansiedades ou desejos, perturbadores da estabilidade emocional, que o levem a necessitar colocar-se mentalmente fora da relação analítica.

Steiner escreveu "O odor que emerge dos recônditos do eu é demasiado fétido [e, ou perfumado, maligno e, ou, amoroso] para ser respirável” (2008, p. 70), contudo existe, poder-se-ia dizer na senda de Galileu Galilei, se o repelirmos abafando-o. É pelo entendimento das nossas profundezas mentais, entranhas, que poderemos entender as vísceras dos outros.

\section{IX}

A partir de 1910, Freud começou a escrever acerca da formação que o psicanalista deveria possuir para o exercício da prática psicanalítica. Disse: "cada avanço em nosso conhecimento [analítico] significa um acréscimo de nosso poder terapêutico" (Freud, 1910a/1996, p.147) e noutro artigo do mesmo ano: 
Não é bastante, pois, para um médico [candidato a psicanalista] saber alguns dos achados da psicanálise; ele deve também estar familiarizado com a técnica se ele deseja que seu procedimento profissional se oriente por um ponto de vista psicanalítico. Esta técnica não pode no entanto ser adquirida nos livros, e ela por certo não pode ser descoberta independentemente, sem grandes sacrifícios de tempo, de cansaço e de sucesso. Como outras técnicas médicas, ela tem de ser aprendida com aqueles que já são experimentados nela (Freud, 1910b/1996, p. 238).

E ainda em 1925, ecreveu o autor que "Uma formação desse gênero [formação psicanalítica] é mais bem executada se a própria pessoa se submete a uma análise e a experimenta em si mesma; a instrução teórica na análise fracassa em penetrar bastante fundo e não traz convicção" (Freud, 1925/1996, pp. 307-308). Freud escreveu em 1926 que "aprender a análise da única maneira possível - submetendo-se eles próprios a uma análise” (Freud, 1926-1927/1996, p. 238). É por aqui que o aprendiz (candidato) inicia o seu ofício, aprendendo e aperfeiçoando a arte de psicanalisar. Quando o analista está na sessão com o seu analisando, o conhecimento que adquiriu nas leituras, nos seminários e nas supervisões, deve estar numa área de sombra da sua mente (pré-consciente), disponível para ser espontaneamente ativado pelas associações livres do paciente, ligando-se a elas e significando-as mas não as invadindo com teorias rotuladoras. Face às comunicações do analisando é fundamental a capacidade de ressonância interna do analista, que deriva da capacidade de conter e permitir-se sentir as repercussões emocionais, que internamente são despoletadas pelo transmitido do analisando. Ou seja, é necessário haver espaço-tempo para acolher e entender o paciente (sentindo e pensando) e para investigar (a realidade da sessão ao se confrontar com as teorias/pensamentos invocadas, poderá reforçá-las, rejeitá-las ou complementá-las), mas não para o analisando ser revestido (moldado) pelas teorias do analista. Como diz Freud na Conferência XXVIII, das Conferências Introdutórias sobre Psicanálise, o paciente só evolui se os pensamentos que o analista lhe comunique "se coadunarem com o que nele é real" (Freud, 1917b/1996, p. 453). Este assunto surgirá também num trabalho de 1940.

Conhecimento e sabedoria não são idênticos. O segundo inclui o primeiro, mas o primeiro não inclui o segundo. A sabedoria psicanalítica evolui do conhecimento teórico e da experiência emocionalmente vivida da prática clínica (donde se originam pensamentos que são pensados e interiorizados) e das qualidades pessoais para 
o ministério. No texto de 1910, Freud escreveu que "nenhum psicanalista [na análise de seus pacientes] avança além do quanto permitem seus próprios complexos e resistências internas" (1910a/1996, p. 150), daí assinalar que o psicanalista "deva iniciar sua atividade por uma autoanálise e levá-la, de modo contínuo, cada vez mais profundamente" (1910a/1996, p. 150). Em nota de rodapé do editor (p. 151) é dito que posteriormente Freud insistia na necessidade de o candidato se submeter a análise didática com um psicanalista (Editor, Freud, 1910a/1996). Em 1913, Freud explica porque é que a autoanálise é insuficiente para o candidato:

mesmo um homem que é muito bem capaz de realizar uma análise em outras pessoas possa comportar-se como qualquer outro mortal e ser capaz de produzir as mais intensas resistências, assim que ele próprio se torna objeto da investigação analítica. Quando isto acontece, somos mais uma vez relembrados da dimensão da profundidade da mente, e não nos surpreende descobrir que a neurose [a patologia mental] tem suas raízes em estratos psíquicos nos quais o conhecimento intelectual da análise não penetrou (Freud, 1913a/1996, p. 142).

Daí ser necessário "uma psicanálise estritamente regular e forte, que não tenha medo de manejar os mais perigosos impulsos mentais e de obter domínio sobre eles, em benefício do paciente" (Freud, 1915/1996, p. 188), pela qual o psicanalista tenha passado, de modo a que ele próprio possa encarnar esse espírito destemido e com os seus analisandos ir até ao mais profundo do ser.

Freud, em 1910, ao focar os contributos positivos e negativos do psicoterapeuta para o processo psicanalítico, aborda a contratransferência do analista que surge "como resultado da influência do paciente sobre os seus sentimentos inconscientes" (Freud, 1910a/1996, p. 150). Mais tarde Freud irá abordar, novamente, o tema da contratransferência. Não só a contratransferência, como toda a relação inconsciente do psicanalista para com o analisando necessita tornar-se consciente (enquanto inconsciente é perturbadora do processo analítico, mas analisada e tornada consciente é importante para entender e interpretar o analisando e a si próprio), porque como diz Freud (1915/1996) a capacidade de analisarmos o outro depende da que formos capazes em relação a nós mesmos. Mas não só áreas inconscientes do analista poderão interferir negativamente, nalgumas situações desastrosamente, no processo analítico dos seus pacientes, também conscientemente (tenho esperança que sejam raros os casos) poderá enredar-se com o seu analisando, agindo necessidades e desejos amo- 
rosos, agressivos, narcísicos e outros desadequados ao contexto analítico. Releva-se daqui ser fulcral, visceral para a boa prática psicanalítica, a qualidade, extensão e profundidade da análise pessoal do analista, pois ela é o alicerce do processo construtivo de um analista. Análise pessoal onde tenha vivenciado, pensado e entendido o seu mundo interno e as suas relações com o mundo externo. É a boa análise pessoal que permite a expansão mental dentro do indivíduo e o expandir-se para o mundo externo, relacionando-se e realizando-se, criando uma relação dinâmica de criatividade e de benefícios mútuos entre esses dois mundos. A extrema importância da análise pessoal para o analista não se resume a tornar consciente o inconsciente, bem pelo contrário, é toda a vivência emocional que decorre e se torna possível na relação entre psicanalista e analisando durante todo o processo psicanalítico, é o reviver velhas relações (transferência) e o viver a realidade da "nova relação" (Matos, 2016) com o seu analista (parece-me que em sentido semelhante irá o pensamento de Freud de 1937 quando disse "nem toda boa relação entre um analista e seu paciente, durante e após a análise, devia ser encarada como transferência [positiva]; havia também relações amistosas que se baseavam na realidade e que provavam ser viáveis" (Freud, 1937/1996, p. 237)), é o viver a relação continente (analista)-conteúdo (analisando) num "vínculo simbiótico" (Bion, 1991b) e o adquirir (desenvolver) a "função psicanalítica da personalidade" (Bion, 1991a), a qual lhe permitirá dar continuidade à sua análise pessoal, finda esta, através da autoanálise, possibilitando-lhe analisar em si e nas relações com o mundo externo novos elementos desconhecidos.

\section{$\mathbf{X}$}

Em 1911 Freud escreveu que "a resposta a questões de técnica em análise nunca é coisa rotineira” (Freud, 1911/1996, p. 101), ou seja, a técnica tendo os seus alicerces estabelecidos, não é contudo pré-formatada e universal para todos os analistas, basta pensar nos diversos enfoques das diferentes correntes psicanalíticas e na personalidade de cada psicanalista. E em 1912 escreveu "esta técnica é a única apropriada à minha individualidade; não me arrisco a negar que um médico constituído de modo inteiramente diferente possa ver-se levado a adotar atitude diferente em relação a seus pacientes e à tarefa que se lhe apresenta" (Freud, 1912/1996, p. 125). Portanto, o modo de estar com o analisando, de vivenciá-lo e pensá-lo não é uniforme para todos os analistas, como não é uniforme o modo como o mesmo psicanalista analisa cada 
um dos seus analisandos, os quais se inserem em diferentes modos de funcionamento mental, à semelhança da relação do pai e da mãe com cada um dos seus filhos, de idades e sexos diferentes e ao longo de diferentes etapas das suas vidas. Neste mesmo trabalho de Freud de 1912 lemos "a regra de prestar igual reparo a tudo [para o analista, em relação ao que o analisando lhe comunica, ou seja a "atenção flutuante"] constitui a contrapartida necessária da exigência feita ao paciente, de que comunique tudo o que lhe ocorre, sem crítica ou seleção ["regra da associação livre"]" (Freud, 1912/1996, p. 126). Se o analista, pelas suas expectativas, interesses ou defesas, selecionar ou ocultar de si próprio parte(s) da sessão, será conduzido "a nunca descobrir nada além do que já sabe [quer do paciente quer de si próprio] [... e] certamente falsificará o que possa perceber" (Freud, 1912/1996, p. 126).

É importante não pensarmos que sabemos o que o paciente quis dizer quando a comunicação não ficou clara para nós. Nessa situação há que investigar, aprofundar/ esclarecer o assunto, senão a projeção do analista irá sobrepor-se à investigação, à verdade do analisando. Nestas ocasiões, através de questões/interpretações exploratórias dirigidas ao analisando poderemos tentar entender melhor a realidade interna e externa do paciente, e ele próprio ficar mais consciente delas, permitindo-nos interpretar, então, com maior rigor e verdade. No mesmo artigo de 1912, um pouco mais adiante, Freud escreveu que o analista "deve voltar seu próprio inconsciente, como um órgão recetor, na direção do inconsciente transmissor do paciente" (Freud, 1912/1996, p. 129). E em 1913 escreveu "todos possuem, em seu próprio inconsciente, um instrumento com que podem interpretar as elocuções do inconsciente das outras pessoas" (Freud, 1913b/1996, p. 344), significando que atingimos verdadeiramente a atenção flutuante quando, conseguimos usar o funcionamento do nosso inconsciente para contactar diretamente com o do paciente, na relação com este, permitindo-nos descortinar e torná-los conscientes os pensamentos inconscientes contidos nas comunicações do analisando. Este trabalho só é possível ser realizado plenamente quando a própria análise pessoal do analista conseguiu chegar ao âmago do ser, quando não permaneceram no seu mundo interno zonas ou pontos semelhantes a buracos negros existentes no universo, partes não analisadas, que o cegam também em relação a partes da mente do seu analisando, tirando-lhe disponibilidade para com este se relacionar nessas áreas desconhecidas e temidas, ficando assim coartada a "nova relação" (Matos, 2016) entre ambos.

De um outro ângulo, e ainda relativo à atenção flutuante, Freud no mesmo escrito de 1912 refere que o psicanalista "deve simplesmente escutar e não se preocupar se 
está se lembrando de alguma coisa" (Freud, 1912/1996, p. 126), ou seja "abandonar-se inteiramente à 'memória inconsciente"' (Freud, 1912/1996, p. 126), significando que o analista não deve ter a preocupação de memorizar. Elementos de sessões anteriores tornar-se-ão espontaneamente conscientes através de memória associativa, ao serem evocados pelos elementos da sessão presente. Nesta linha de pensamento insere-se Bion quando diz que "o analista é tornado infinito pelo despojar-se de memória, desejo, compreensão" (Bion, 1991b, p.56), portanto o analista (em continente vazio) fica infinitamente disponível para tudo acolher em si (e poder pensar e dar sentido aos contidos para os interpretar) quer vindo de si mesmo ou do analisando, nomeadamente a vivência de experiências mentalmente dolorosas. A abertura mental do analista para as suas emoções e pensamentos e para as do analisando é fundamental para permitir a expansão da mente de ambos, possibilitando-lhes caminharem para a raiz do ser pessoal.

\section{XI}

Freud na Conferência XXVII diz que "[os conselhos e orientações nos assuntos da vida do paciente não fazem parte do processo psicanalítico, o que se pretende é] que o paciente venha a tomar as decisões por si mesmo [...] a se conduzir de acordo com a verdade referente a si mesmo" (Freud, 1917a/1996, pp. 435-436). E em 1923 diz que:

o objetivo do tratamento [...é obter] do paciente o melhor que suas capacidades herdadas permitam, e tornando-o assim tão eficiente e capaz de gozo quanto é possível [...] O analista respeita a individualidade do paciente e não procura remoldá-lo de acordo com suas próprias ideias pessoais, isto é, as do médico; contenta-se com evitar dar conselhos e, em vez disso, com despertar o poder de iniciativa do paciente (Freud, 1923/1996, p. 267).

Estas duas citações representam o objetivo príncipe da psicanálise, juntamente com a resolução da dor mental patológica do paciente. No processo psicanalítico é crucial o interesse do analista pela pessoa do analisando e não tanto pela doença mental deste. $\mathrm{O}$ interesse pelo germe desse ser humano cuja expansão está inibida, aprisionada na doença, causando-lhe dor mental, devido à falta de relações afetuosas, de entendimento, valorizadoras, e de ajuda, que o fizessem sentir-se desejado, amado 


\section{O Ser Psicanalista}

e respeitado e lhe possibilitassem amar. A expansão da mente, realizada na relação psicanalista-paciente, quebra as grilhetas psicopatológicas, permitindo ao indivíduo revelar-se na sua pujança.

Freud enfoca a modificação psíquica no analisando através do tornar consciente o inconsciente. Mas, como já atrás afirmámos, isso é apenas uma parte daquilo que de fundamental existe no processo psicanalítico, que conduz a essa modificação. Dissemos que vários outros elementos são peças-chave desse processo, como por exemplo, a "relação continente (psicanalista) - conteúdo (analisando)" (Bion, 1991a) e a "nova relação" (Matos, 2016), assim como o são o desbloquear e potencializar as forças internas dinâmicas de desenvolvimento e o desvendar mais integralmente o "verdadeiro self" (Winnicott, 1988) ou na linguagem de Bion (1982) o evoluir para "O" (na terminologia empregada por Bion a letra O designa a realidade psíquica última desconhecível diretamente, podendo apenas ser conhecível através do produto de suas transformações). Este conjunto de dinâmicas, decorrendo favoravelmente, conduz ao que Freud escreveu, na referida Conferência XXVII, que "O neurótico realmente curado tornou-se outro homem [...] tornou-se o que se teria tornado na melhor das hipóteses, sob as condições [de vida] mais favoráveis" (Freud, 1917a/1996, p. 437).

$\mathrm{O}$ analista sabe que o caminho da análise que pode conduzir o paciente a tender para “O” é muitas vezes duro, mas é através dele que poderá conseguir realizá-lo.

\section{XII}

No ano de 1918 Freud escreveu que:

A novidade [que contribui para o progresso do conhecimento psicanalítico] só pode ser obtida de análises [...] que a elas se dedique bastante tempo. Apenas em tais casos conseguimos descer aos estratos mais profundos e mais primitivos do desenvolvimento mental e destes obter soluções para os problemas das formações posteriores (Freud, 1918, p. 21).

Este pensamento de Freud conduz-nos em vários sentidos. Por um lado, é fundamental que o analista na sua análise pessoal vá aos fundos de si mesmo e consiga entendê-los para poder viajar sem receio nos fundos dos outros e dar-lhes sentidos. 
Por outro lado, este trabalho leva tempo, mesmo numa relação entre um analista com saber e um paciente colaborante. Estabelecer uma relação de confiança e emocionalmente (não intelectualmente) mergulhar nas profundidades do ser, leva tempo. $\mathrm{O}$ aspeto da "novidade" referido neste pensamento de Freud relaciona-se com um outro, inserido no mesmo artigo umas páginas adiante:

só estou relatando [do caso do Homem dos Lobos] o que surgiu como experiência independente, não influenciada pela minha expectativa. De forma que nada mais me restou senão recordar a sábia sentença de que há mais coisas no céu e na terra do que sonha a nossa filosofia ["Há mais coisas no Céu e na Terra, Horácio, do que sonha a nossa filosofia" (Shakespeare, n.d., p. 32) - no sentido que a realidade ultrapassa a capacidade de pensar, imaginar]. Qualquer um que pudesse conseguir eliminar ainda mais completamente as suas convicções preexistentes, descobriria, sem dúvida, ainda mais coisas como estas (Freud, 1918/1996, pp. 23-24).

O novo, o desconhecido, o inesperado, o estranho, o diferente, o tender para o infinito, só poderão surgir, ser aceites, acolhidos e tolerados pelo analista (e posteriormente pelo analisando) se para isso este estiver internamente disponível e não, por exemplo, saturado com ideias preconcebidas. Uma das dificuldades na investigação durante o processo psicanalítico advém da pressão por parte do paciente e do próprio analista para que se consigam resultados psicoterapêuticos rápidos, pressionando o analista a interpretar, a queimar etapas da análise. É importante que o analista sinta em si uma postura aberta, recetiva e tranquila para com o analisando e para consigo próprio ao invés de postura ansiosa e pressionante. Outra dificuldade no trabalho de investigação poderá advir do sentimento de omnisciência, arrogância e ódio no analista quando se sentindo posto em causa pelo analisando, por este discordar ou atacar o que o analista lhe havia transmitido. Se estas emoções surgirem no psicanalista é crucial serem contidas e analisadas pelo próprio analista, ao invés de agidas, pois iriam atacar a relação analítica e a procura da verdade. É através do sentimento de se sentir acolhido pelo analista que o paciente poderá cada vez mais colaborar livre e espontaneamente no trabalho analítico, e à medida que internamente se sinta consistente poderá confrontar-se, mais amplamente, com o que teme, do passado, do presente e do futuro. 


\section{XIII}

Freud escreveu em 1919 que "o tratamento analítico deve ser efetuado, na medida do possível, sob privação - num estado de abstinência” (Freud, 1919/1996, p. 176). Relaciona a abstinência com "a dinâmica da doença e da recuperação" (Freud, 1919/1996, p. 176) no paciente. O enfoque que me interessa neste meu trabalho é a do psicanalista face a essa dinâmica. É essencial que o analista tenha os seus conflitos e carências resolvidos de modo a não agir a satisfação dos desejos e necessidades do paciente, fragilizado e carente, que direta ou indiretamente lhe manifesta o desejo que lhos satisfaça. Este desejo surge, geralmente, integrado numa relação transferencial paciente/filho - analista/pai-mãe, e visa satisfações sexuais, narcísicas ou outras.

É neste contexto que inserimos também o que Freud escreveu em 1920:

O paciente não pode recordar a totalidade do que nele se acha reprimido, $\mathrm{e}$ o que não lhe é possível recordar pode ser exatamente a parte essencial [...] É obrigado a repetir o material reprimido como se fosse uma experiência contemporânea, em vez de, como o médico preferia ver, recordá-lo como algo pertencente ao passado. Essas reproduções [...] são invariavelmente atuadas (acted out) na esfera da transferência, da relação do paciente com o médico (Freud, 1920a/1996, p. 29).

Como referimos, é indispensável que o analista possua capacidade interna para não se deixar envolver emocionalmente a ponto de agir a sua contratransferência, ou agir até de modo consciente, entre outros, sentimentos amorosos-sexuais ou hostis e ideias interesseiras ou generosas. Consciente de que não é ele mesmo que está na origem daquelas atitudes do seu paciente para consigo (a não ser que na realidade o paciente esteja a reagir a sinais-atitudes desadequados do seu analista), pode acolher e sentir a transferência, pensar o seu significado e comunicá-lo ao seu paciente. De modo diferente procederá o analista que por falhas na formação pessoal e na sua análise, ou por sobrecarga emocional e mental momentânea, ou outras, o levem a reagir, transformando a transferência (acontecimento vindo do passado) num acontecimento do presente. No contexto transferencial é importante colocar o foco de análise no recordar do paciente (recordar emocionalmente - reviver dentro de si episódios significativos do passado) porque possibilita a perspetiva do paciente e do analista a trabalhar em conjunto face a um terceiro (o objeto de investigação e análise) e não 
como agentes ativos (que agem) envolvidos nesse cenário do passado/presente. Ao invés do contexto transferencial, no contexto da "nova relação" (Matos, 2016), aí sim, o foco de análise poderá envolver também a relação atual (a nova relação) intersubjetiva (relacionando dois mundos internos) entre o psicanalista e o analisando.

\section{XIV}

Em 1920, Freud disse que:

o próprio paciente se apossa do material que lhe foi apresentado [no decorrer da análise pelo psicanalista]; trabalha sobre ele, recorda-se do que pode de lembranças aparentemente reprimidas e tenta repetir o resto, como se de alguma forma $o$ estivesse vivendo novamente. Pode assim confirmar, suplementar e corrigir as inferências do médico. Só durante esse trabalho que ele experimenta, pela vitória sobre as resistências, a mudança interior a que visa e adquire para si as convicções que o tornam independente da autoridade do médico (Freud, 1920b/1996, p. 163).

No decurso da investigação no processo analítico é através da vivência da verdade emocional, do pensar (pensamentos e emoções) e do fazer sentido para o analisando (emergidos da relação analista-analisando, onde este se sente acolhido e entendido e vai-se entendendo através das interpretações do analista e onde lhe é permitido ir sendo ele próprio) que este vai interiorizando e desenvolvendo a "função psicanalítica da personalidade" (Bion, 1991a), autonomizando-se progressivamente da pessoa do analista. Possuir e utilizar-se desta função é de importância extrema, pois é ela que vai permitir ao analisando dar continuidade à sua análise pessoal através da autoanálise e como psicanalista, também, analisar os seus analisandos.

\section{XV}

Em 1927, Freud escrevia que:

Nós que somos analistas pomos diante de nós como nosso objetivo a análise mais completa e mais profunda possível de quem quer que possa ser nosso pa- 


\section{O Ser Psicanalista}

ciente [...] procuramos enriquecê-lo a partir de suas própria[s] fontes internas, colocando à disposição do seu ego aquelas energias que, devido à repressão, se acham inacessivelmente confinadas em seu inconsciente, bem como aquelas que seu ego é obrigado a desperdiçar na tarefa infrutífera de manter essas repressões (Freud, 1926-1927/1996, pp. 245-246).

E em 1937 escreveu que "o objetivo terapêutico [...] era [...] o de exaurir as possibilidades de doenças neles [casos clínicos] e ocasionar uma alteração profunda de sua personalidade" (Freud, 1937/1996, p. 240). Esta alteração de personalidade realiza-se através da evolução do funcionamento patológico para “O” (Bion, 1982), ultrapassando fragilidades (derivadas de processos de desenvolvimento que não se completaram, mas enveredaram por vias sem saída ou por caminhos retorcidos) pela expansão das capacidades afetivo-relacionais-cognitivas.

À semelhança de Freud penso que a análise de um paciente deverá ser a mais profunda e extensamente possível. Como tenho referido, isto implica, por um lado que o analista esteja internamente disponível para realizar essa psicanálise, ou seja, que a sua autoanálise esteja em processo de expansão, encarando como benéfico, ainda que podendo ser mentalmente doloroso, o entrar em contacto com aspetos próprios internos não completamente analisados, no decorrer da relação analítica com o seu paciente, e por outro que o analisando esteja disponível para os custos (psíquicos, de tempo e monetários) que essa análise implica, por vezes difícil de se coadunar com os tempos atuais onde se valoriza a aparência, o superficial e o prazer imediato. Relativamente à libertação de "energias", elas servirão para impulsionar o processo de o analisando se realizar naquilo que ele verdadeiramente é, aspeto que vai (re)descobrindo ao longo do trabalho de pesquisa analítica na relação com o seu psicanalista, desenvolvendo a "função psicanalítica da personalidade" (Bion, 1991a), a capacidade de relacionar-se amando e sendo amado, aceitando-se e aceitando o outro, a capacidade criativa, a curiosidade e interesse pelo novo. É a análise profunda, numa perspetiva de relacionar o passado com o presente e o futuro que permite a expansão do mundo interno e deste para o mundo externo, abrindo-se às relações com os outros e evoluindo nelas. É do seu verdadeiro ser que emerge a sua força pessoal afirmativa no mundo. E é essa força interna, essa individualidade, que é necessário que o meio ambiente acolha e incentive, de modo a que cada indivíduo realizando-se no que lhe é próprio, contribua para um mundo de seres diversos e complementares, onde a cooperação, a amizade, o amor e a criatividade se sobreponham à competição invejosa destrutiva e ao ódio. 


\section{REFERÊNCIAS}

Bion, W.R. (1982). Transformations: Passage de l'Apprentissage à la Croissance. Paris: Presses Universitaires de France.

Bion, W.R. (1991a). O Aprender com a Experiência. Rio de Janeiro: Imago Editora.

Bion, W.R. (1991b). A Atenção e Interpretação: O Acesso Científico à Intuição em Psicanálise e Grupos. Rio de Janeiro: Imago Editora.

Bion, W.R. (1994). Estudos Psicanalíticos Revisados (Second Thoughts) (3a edição). Rio de Janeiro: Imago Editora.

Freud, S. (1889/1996). Resenha de Hipnotismo, de August Forel. In Edição Standard Brasileira das Obras Psicológicas Completas de Sigmund Freud, Volume I, 125140. Rio de Janeiro: Imago Editora.

Freud, S. (1895/1996). Estudos Sobre a Histeria: IV A Psicoterapia da Histeria. In Edição Standard Brasileira das Obras Psicológicas Completas de Sigmund Freud, Volume II, 269-316. Rio de Janeiro: Imago Editora.

Freud, S. (1900/1996). A Interpretação dos Sonhos (Primeira Parte): Capítulo II O Método de Interpretação dos Sonhos: Análise de um Sonho Modelo. In Edição Standard Brasileira das Obras Psicológicas Completas de Sigmund Freud, Volume IV, 131-155. Rio de Janeiro: Imago Editora.

Freud, S. (1904/1996). O Método Psicanalítico de Freud. In Edição Standard Brasileira das Obras Psicológicas Completas de Sigmund Freud, Volume VII, 233-240. Rio de Janeiro: Imago Editora.

Freud, S. (1905/1996). Tratamento Psíquico (ou Anímico). In Edição Standard Brasileira das Obras Psicológicas Completas de Sigmund Freud, Volume VII, 267-288. Rio de Janeiro: Imago Editora.

Freud, S. (1910a/1996). As Perspetivas Futuras da Terapêutica Psicanalítica. In Edição Standard Brasileira das Obras Psicológicas Completas de Sigmund Freud, Volume XI, 143-156. Rio de Janeiro: Imago Editora. 
Freud, S. (1910b/1996). Psicanálise 'Silvestre'. In Edição Standard Brasileira das Obras Psicológicas Completas de Sigmund Freud, Volume XI, 229-239. Rio de Janeiro: Imago Editora.

Freud, S. (1911/1996). O Manejo da Interpretação de Sonhos na Psicanálise. In Edição Standard Brasileira das Obras Psicológicas Completas de Sigmund Freud, Volume XII, 97-106. Rio de Janeiro: Imago Editora.

Freud, S. (1912/1996). Recomendações aos Médicos que Exercem a Psicanálise. In Edição Standard Brasileira das Obras Psicológicas Completas de Sigmund Freud, Volume XII, 121-133. Rio de Janeiro: Imago Editora.

Freud, S. (1913a/1996). Sobre o Início do Tratamento (Novas Recomendações Sobre a Técnica da Psicanálise I). In Edição Standard Brasileira das Obras Psicológicas Completas de Sigmund Freud, Volume XII, 135-158. Rio de Janeiro: Imago Editora.

Freud, S. (1913b/1996). A Disposição à Neurose Obsessiva: Uma Contribuição ao Problema da Escolha da Neurose. In Edição Standard Brasileira das Obras Psicológicas Completas de Sigmund Freud, Volume XII, 335-349. Rio de Janeiro: Imago Editora.

Freud, S. (1915/1996). Observações Sobre o Amor Transferêncial (Novas Recomendações Sobre a Técnica da Psicanálise III). In Edição Standard Brasileira das Obras Psicológicas Completas de Sigmund Freud, Volume XII, 173-188. Rio de Janeiro: Imago Editora.

Freud, S. (1917a/1996). Conferências Introdutórias Sobre Psicanálise: Parte III Teoria Geral das Neuroses; Conferência XXVII Transferência. In Edição Standard Brasileira das Obras Psicológicas Completas de Sigmund Freud, Volume XVI, 433448. Rio de Janeiro: Imago Editora.

Freud, S. (1917b/1996). Conferências Introdutórias Sobre Psicanálise: Parte III Teoria Geral das Neuroses; Conferência XXVIII Terapia Analítica. In Edição Standard Brasileira das Obras Psicológicas Completas de Sigmund Freud, Volume XVI, 449-463. Rio de Janeiro: Imago Editora. 
Freud, S. (1918/1996). História de uma Neurose Infantil. In Edição Standard Brasileira das Obras Psicológicas Completas de Sigmund Freud, Volume XVII, 13-127. Rio de Janeiro: Imago Editora.

Freud, S. (1919/1996). Linhas de Progresso na Terapia Psicanalítica. In Edição Standard Brasileira das Obras Psicológicas Completas de Sigmund Freud, Volume XVII, 169-181. Rio de Janeiro: Imago Editora.

Freud, S. (1920a/1996). Além do Princípio de Prazer. In Edição Standard Brasileira das Obras Psicológicas Completas de Sigmund Freud, Volume XVIII, 11-75. Rio de Janeiro: Imago Editora.

Freud, S. (1920b/1996). A Psicogênese de um Caso de Homossexualismo numa Mulher. In Edição Standard Brasileira das Obras Psicológicas Completas de Sigmund Freud, Volume XVIII, 155-183. Rio de Janeiro: Imago Editora.

Freud, S. (1923/1996). Dois Verbetes de Enciclopédia: (A) Psicanálise. In Edição Standard Brasileira das Obras Psicológicas Completas de Sigmund Freud, Volume XVIII, 249-270. Rio de Janeiro: Imago Editora.

Freud, S. (1925/1996). Prefácio a Juventude Desorientada, de Aichhorn. In Edição Standard Brasileira das Obras Psicológicas Completas de Sigmund Freud, Volume XIX, 303-308. Rio de Janeiro: Imago Editora.

Freud, S. (1926-1927/1996). A Questão da Análise Leiga: Conversações com uma Pessoa Imparcial/Pós-Escrito. In Edição Standard Brasileira das Obras Psicológicas Completas de Sigmund Freud, Volume XX, 173-248. Rio de Janeiro: Imago Editora.

Freud, S. (1932/1996). Meu Contato com Josef Popper-Lynkeus. In Edição Standard Brasileira das Obras Psicológicas Completas de Sigmund Freud, Volume XXII. 209-218. Rio de Janeiro: Imago Editora.

Freud, S. (1937/1996). Análise Terminável e Interminável. In Edição Standard Brasileira das Obras Psicológicas Completas de Sigmund Freud, Volume XXIII, 223270. Rio de Janeiro: Imago Editora. 
OSer Psicanalista

Freud, S. (1940/1996). Esboço de Psicanálise. In Edição Standard Brasileira das Obras Psicológicas Completas de Sigmund Freud, Volume XXIII, 151-221. Rio de Janeiro: Imago Editora.

Matos, A.C. (2002). Psicanálise e Psicoterapia Psicanalítica. Lisboa: Climepsi Editores.

Matos, A.C. (2016). Nova Relação. Lisboa: Climepsi Editores.

Shakespeare, W. (n.d.). Hamlet (2 ${ }^{a}$ edição). Mem Martins: Publicações Europa-América.

Steiner, G. (2008). Os Livros que não Escrevi. Lisboa: Gradiva.

Winnicott, D.W. (1988). O Ambiente e os Processos de Maturação: Estudos Sobre a Teoria do Desenvolvimento Emocional (2a edição). Porto Alegre: Artes Médicas. 